Orbis Tertius, vol. XXII, n ${ }^{\circ}$ 25, e036, junio 2017. ISSN 1851-7811

Universidad Nacional de La Plata

Facultad de Humanidades y Ciencias de la Educación

Centro de Estudios de Teoría y Crítica Literaria

\title{
Las aventuras sado-masoquistas de un lion en cage: una lectura queer de la obra El mendigo chupapijas
}

\author{
Natalia Lorena Zorrilla * \\ * Universidad de Buenos Aires - Université Paris-Sorbonne, Argentina
}

\section{PALABRAS CLAVE}

El mendigo chupapijas

Literatura argentina queer

Belleza y Felicidad

Sado-masoquismo

\section{EYWORDS}

El mendigo chupapijas

Queer Argentinean literature

Belleza y Felicidad

Sado-masochism

\section{RESUMEN}

Este artículo recorre la obra de Pablo Pérez El mendigo Chupapijas con el objetivo de estudiar su propuesta estética trash y queer, basada en la apropiación literaria que éste realiza del sado-masoquismo y de los espacios asociados a estas prácticas. Observamos aqui la valorización que Pérez ofrece de la sexualidad vagabunda y el cruising de su escritura, a partir del cual se topa con distintos roles sexuados y de poder, asi como también con un collage de diversos géneros discursivos que incluye y adopta. Se trata entonces aqui de reflexionar sobre esta intervención cultural que Pérez engendra, examinando el dimensionamiento politico de la representación que éste ofrece de la lucha por afirmar la propia identidad.

ABSTRACT
This article examines Pablo Pérez's work El mendigo chupapijas with the aim of studying
his trash and queer aesthetic, focusing on his literary appropriation of sado-masochism
and of the spaces associated with these practices. We observe Pérez's account of a
vagabond sexuality and the cruising in his writing, throughout which he encounters
different sexual roles of power as well as a collage of diverse discursive genres which he
seeks to include and adopt in his eclectic novel. We therefore seek to analyse the political
dimensioning encompassed in this cultural intervention that Pérez produces, focusing on
the representation the author offers of the struggle to affirm one's identity.

Cita sugerida: Zorrilla, N. L. (2017). Las aventuras sado-masoquistas de un lion en cage: una lectura queer de la obra El mendigo chupapijas. Orbis Tertius, 22(25), e036. https://doi.org/10.24215/18517811e036 


\section{Acerca de la circulación y publicación del Mendigo Chupapijas}

El Mendigo Chupapijas compila una serie de aventuras, conversaciones y reflexiones sobre el sexo y la muerte de Pablo, el protagonista de la novela, un joven escritor y traductor algo enamoradizo y dado a la experimentación sexual particularmente enfocada al fetichismo y al masoquismo tanto leathercomo romántico. Se publicó a través del sello Belleza y Felicidad como un folletín por entregas entre los años 1999 y 2000. Posteriormente, adquirió el formato libro, reeditándose en el año 2005 por Mansalva y tuvo además dos versiones cinematográficas: un cortometraje dirigido por el mismo Pablo Pérez del año 2009 y un largometraje dirigido por Anahí Berneri y adaptado por Pérez tomando tanto El mendigo chupapijas como Un año sin amor (esta última, una novela cuya diégesis parece continuarse en la primera).

La distribución inicial de la obra la habría realizado el mismo Pablo Pérez, quien solía vender hojas impresas por él mismo dentro de un sobre en eventos como inauguraciones y lecturas. Así fue como Fernanda Laguna, co-fundadora de Belleza y Felicidad junto con Cecilia Pavón $\underline{1}$, entra en contacto con el texto de Pérez, convirtiéndolo en la primera publicación de la editorial. "ByF” (que funcionó además como una galería de arte gestionada y sostenida por sus creadoras disolviéndose definitivamente en 2007) producía, tal como describe Pérez, unos "libritos fotocopiados" (Palmeiro 2011: 182) cuya estética estaba inspirada en la literatura del cordel brasileña. Este formato resultaba accesible popularmente y, por lo tanto, rupturista respecto de una concepción elitista y sectaria de la literatura, lo cual abonaba al proyecto de la editorial desde donde se celebraba el fenómeno de la escritura no como consagración sino como transmisión de nuevas historias e identidades festivas y alternativas, marginadas por los circuitos literarios mainstream.

De apariencia paradójica, el trabajo de recuperación de la cotidianeidad (y la liviandad o hasta frivolidad que su estetización aporta a la poética de ByF) resultaría ser una forma de intervención artística que pretende operar sobre el tejido social — pudiendo interpretarse como una forma de "arte político". $\underline{2}$ Tal como sostiene Marina Yuszczuk (2015) en un artículo publicado en esta misma revista, el proyecto ByF habría generado en sus intérpretes y críticos, por este motivo, una rotunda estupefacción. Según Yuszczuk, la perplejidad ante el contenido de las obras los habría llevado a privilegiar en sus comentarios la "tarea de gestión” (Yuszczuk 2015: 23) llevada a cabo por los integrantes de dicho emprendimiento. En este sentido, César Aira (2002), por ejemplo, se habría concentrado en destacar el carácter combativo de ByF, reduciéndolo casi a un gesto de espontaneidad y resistencia, en un contexto socio-político de crisis (fines de los noventa y comienzos de los años 2000), adverso al surgimiento de manifestaciones artísticas. ByF representaría así una fuente de inspiración dado que su mera existencia constataba el hecho de que simplemente bastaba con alquilar un local en Almagro, ciudad de Buenos Aires ${ }^{3}$, y convocar amigos e interesados por la cultura para hacer surgir al arte en su “ilusión” autónoma.

Ahora bien, ¿Qué tipo de representaciones o manifestaciones se ponen en juego a través de ByF y cuál es su incidencia política? ¿Qué clase de determinación en relación a lo social se expresa en las "miniaturas banales, encantadoras y plásticas” (García Helder y Prieto 1998, citado en Yuszczuk 2015: 23) de Fernanda Laguna o en esas primeras cartas-páginas del Mendigo chupapijas?

Si hurgar en la simpleza de los materiales más inmediatos y accesibles (como los libros a cordel) o de los sentimientos "más ingenuos y francos" (como los de la niñez) fue lo que definió a ByF, Pablo Pérez no fue ajeno, en El mendigo chupapijas a esta línea de trabajo y expresión. Exploraremos a continuación la infantilización de Pablo, el protagonista de la ecléctica novela, y su progresivo amancebamiento lumpen.

\section{Masoquismo e infancia}

Mendicante desde un principio, la obra de Pérez se aprovisiona en su búsqueda nómada de distintos personajes y certezas que se revelarán descartables, dinámica que permite que la historia de vida de Pablo 
quede sin resguardo y avance hacia su desquicio. Dicha búsqueda se disparará a partir del encierro vivido por él en escenarios como el Cine Box, las comunidades endogámicas SM como el Club Leather o el departamento (y rol familiar) en donde convive a regañadientes con su tía Nefritis. El masoquismo en Pablo, su goce como sumiso, se nos revela desde las primeras líneas de la novela: "Creo que no hay nada más excitante que estar con alguien que puede llegar a ser peligroso y a la vez protector” (Pérez 2005: 52).

Finalmente, el lion en cage $e^{4}$ termina liberándose hacia el desenlace de la novela en donde ocurre que Pablo, cuyo significado en latín es hombre pequeño y humilde, se convierte en Paulita, su hipérbole por más de una razón. El diminutivo, en principio, lo evidenciaría de forma directa. No obstante, Paula resulta ser la hermana de Pablo, de cuyo trágico suicidio nos enteramos en Un año sin amor. "Paulita" es en realidad el nombre con el que un mendigo grandote y achinado bautiza a Pablo cuando éste es echado de su casa por su familia y marca la completitud de su conversión a la mendicidad.

Esta transformación, en la cual el erotismo místico va adquiriendo cada vez más importancia, se manifiesta como una expansión e intensificación del masoquismo en Pablo a la vez que reúne todas las características de una regresión hacia la infancia. La referencia a Paula no es el único indicador en este sentido. La novela concluye con una pregunta que este mendigo que cuida de Paulita le hace a ella (“¿Estás bien Paulita?” [Pérez 2005: 77]), sin obtener ninguna respuesta verbal. Allí es donde el relato cesa, allí es donde Pablo, devenido Paulita, captado por fuerzas superiores como el Amor Universal, pierde definitivamente su habla y se convierte en un ser del balbuceo (Quignard, 2014). Es para él (o para ella) un momento de iluminación en donde lograr escapar de una vez y para siempre de la masculinidad hetero-normativa que signa la adultez y alcanzar el placer del renacimiento asociado a la denegación masoquista (Deleuze 1969: 88). Tal como sostiene Gilles Deleuze en Présentation de Sacher-Masoch. Le froid et le cruel [1967], "El masoquista narra una historia como el elemento suprapersonal que lo anima y es arrastrado por esta historia que describe [...] cómo surgió de allí el Hombre nuevo” (Deleuze 1969: 89-90).

Esta vuelta hacia el pasado se activa desde el momento en que Pablo se da cuenta, al comienzo de la novela, de que quien tantas veces le había realizado sexo oral (a él como a tantos otros) era un mendigo, percatación ante la cual Pablo siente "la resonancia de una vida anterior" (Pérez 2005: 10). Este mendigo voraz goza colmando su boca de miembros, obliterando la posibilidad del habla, manifestando a su vez un total desinterés por cualquier otro tipo de relación que no sea la de chupar la pija de otro (en este sentido, cuando Pablo intenta acercarse a él e iniciar una conversación, es rechazado vehementemente con una profusión de insultos y una posterior huída del mendigo). Este personaje entonces intenta ponerse fuera del sistema, fuera del lenguaje y volverse puro cuerpo, pura cavidad, aunque su marginalidad sólo parece tener sentido en contraste con la figura de la Ley (o de la interdicción internalizada).

La subjetivación masoquista de Pablo se va construyendo como la llave que abre el portal hacia la mendicidad. El paralelismo entre Pablo en su rol de esclavo y el mendigo chupapijas está continuamente sostenido, en primer lugar, por su posición corporal: arrodillados, debiendo levantar la mirada para observar el rostro de sus amantes, lamiendo las botas de su master, se encuentran en la típica postura del infante al fijar el fetiche. En efecto, tal como expone Deleuze, el fetiche, ese objeto de deseo que limita y determina el goce, es en realidad el sustituto del falo femenino que el masoquista deniega; se trata del "último objeto que ha visto, siendo niño, antes de percibir esa ausencia” (Deleuze 1969: 29). Además, ambos reciben un trato tierno y condescendiente cuando "se portan bien" (e.g.: las caricias suaves en la cabeza), característica evocación de la experiencia del infante (y de la mascota -o animalidad derrotada) ante los adultos.

A su vez, la piedad funciona para ellos como safe-house, como un templo que acoge a los desprotegidos: nuestro mendigo pedía limosna en las escalinatas de la Iglesia de la Piedad mientras que Pablo utilizaba “piedad” como palabra clave para detener el juego SM de dominación cuando se franqueaba el límite de lo 
tolerable.

Al consumarse la fusión entre uno y otro, la historia recomienza infinitamente, rindiendo tributo a la potencia infernal de la repetición y el rodeo en la que se basa la resexualización masoquista de lo tanático.

\section{Queer trash}

La estética queer trash a la cual El mendigo chupapijas nos somete reclama para sí la sensibilidad sexodislocante de Copi, Puig, Lamborghini y Perlongher a partir de la cual la obra explora los recovecos, excesos y posibilidades de una sexualidad extrañada en la(s) comunidad(es) del leatherfolk. En efecto, la "literatura experimental" de Pérez es una peculiar "puesta en discurso" de la sexualidad (Foucault, 1976) que abre un juego prolífico a partir del cual pende sobre la lectura la interpelación que esa singularidad queer de Pablo impone, en tanto trae consigo el gesto de la afirmación de cierta identidad de búsqueda sexual y afectiva pero también la incomprensión y la humillación que unifica en su contra al conjunto de sus acusadores. Tal como sostiene Butler en Bodies that matter [1993], "La palabra 'queer' adquiere su fuerza precisamente de la invocación repetida que terminó vinculándola con la acusación, la patologización y el insulto” (Butler 2002: 318) y esta repetición del acto de habla a partir del cual se señala al "raro" avergonzándolo (en el ejemplo de Butler, el raro sería sobre todo el homosexual) es la que asienta la heterosexualización del lazo social actuando asimismo como el "tabú vergonzante que 'perturba' [queers] a aquellos que se resisten o se oponen a esa forma social, así como a aquellos que la ocupan sin la sanción social hegemónica” (Butler 2002: 318)

No obstante, esa repetición tiene un potencial subversivo que la narración de Pérez aprovecha eficazmente; pues cada reiteración o evocación del concepto alude a una referencia anterior sin agotarse completamente en ella por lo que puede ser apropiada y resignificada para introducir nuevos sentidos. De esta manera, la visibilización de la dimensión política de la escritura de Pérez permite interpretarla como una intervención de resistencia a la normalización construida desde lo queer a pesar de que, siguiendo a Silvia Delfino en el Prólogo de la antología Aventuras de Belleza y Felicidad,

El estigma devuelto como desafío no [necesariamente] es una marca de identificación positiva sino una exploración de los límites entre experiencia y lenguaje” ya que "La ironía respecto del propio lugar (...) desafía tanto la estética como cualquier estabilidad de género, incluso los poéticos (2001: 5).

Aunque quizás se evidencie más claramente en Un año sin amor, un aporte a la tradición de los diarios sobre el SIDA que se habría inspirado entre otros en los escritos de Hervé Guibert, el acecho de la enfermedad y la muerte registrados desde el testimonio autobiográfico dan sentido a la expresión literaria de Pérez. Perlongher, en El fantasma del sida, decía: "Un fantasma recorre los lechos, los flirts, los callejeos: el fantasma del SIDA. La sola mención de la fatídica sigla [...] basta para provocar una mezcla morbosa de curiosidad y miedo" (Perlongher 1988: 9).

Este fantasma, si bien permanece al acecho, pierde su fuerza en El Mendigo Chupapijas porque Pablo, quien en continuidad con Un año sin amor ya habría asumido su condición de seropositivo, sería ahora asediado por el espectro de la interdicción y el rechazo. Este último estaría ambivalentemente ausente como sensación pero presente como sentimiento en el horizonte vivencial del protagonista. Se manifestaría más claramente en las figuras del padre y de la tía de Pablo, quienes, luego de haber leído su diario íntimo lo ven como "un vago que no trabaja y un degenerado sadomasoquista” (Pérez 2005: 75), opinión a la que se suma la de la tía y la prima evangelistas, según las cuales Pablo sería “un enfermo del corazón alejado de Dios” (Pérez 2005: 75). Así, este doble repudio al Pablo-slave y al Pablo-místico es la sentencia que termina marginándolo definitivamente del sistema de parentesco hetero-normativo sobre el cual reposa la familia burguesa. Pablo se somete al castigo sin poner ninguna resistencia; la falta de tal sistema de protección funciona como una 
liberación o una oportunidad para que él, quien tantas veces había fantaseado con su suicidio o su asesinato a manos de otros, renazca y comience a vivir una nueva vida.

Sin embargo, esta nueva identidad, Paulita, está construida, como hemos visto, a partir de los restos de otras vidas o de otras personalidades traspuestas. Paulita es lo que quedó de Pablo, después de haber estallado en mil pedazos. En este sentido, el trabajo de apropiación y revalorización de lo “desechable”, de lo trash, que Pérez realiza se expande por toda la narración. Los episodios que relata Pablo, muchos de ellos situaciones irresueltas, truncas o eventos con un aire de superficialidad, se vuelven significativos en esta narración: encuentros sexuales fortuitos, penetraciones no consumadas o interrumpidas, tríos románticos incómodos y peligrosos, además de los recorridos por el underground porteño y sus recovecos más marginales. La provocación de incorporar bajezas y vulgaridades en El mendigo chupapijas cumple entonces con la proclama vanguardista de ByF: desacralizar la literatura para incluir sectores, individuos e historias previamente excluidos de la misma. $\stackrel{5}{ }$ Tal como sostiene Palmeiro (2008), quien acuña el término “antiestéticas de lo trash” para referirse a esta cuestión, es notable cómo, a partir de esta reivindicación de los materiales "bajos" o "menores" y de la incorporación de cotidianeidades e "insignificancias", se produce la "politización de lo cotidiano, [...] del cuerpo [y el] despliegue del valor crítico de la diferencia” (Palmeiro 2008: 2).

\section{Camp y subversión}

El devenir lumpen de Pablo es, asimismo, un devenir mujer (Paulita) a partir del cual se ponen de manifiesto al menos dos ideas típicamente asociadas a una poética camp (Amícola 2000): la desnaturalización posmoderna de las categorías de género o gender y la idea de una lucha por afirmar la [propia] sexualidad a través de su visibilización exacerbada. Lo camp, según explica José Amícola, es una "manifestación del discurso queer frente a la imposibilidad de asumirse como persona bajo la presión heterosexual compulsiva y los vínculos enunciativos del orden dominante" (Amícola 2000: 50), lo que sintetiza y da sentido al cambio de vida de Pablo y su conversión a la feminidad en El mendigo chupapijas.

Si bien lo camp ha sido históricamente asociado a las Drag Queens por sus formas teatrales sobrecargadas, artificialidad y exageración (Sontag 2008), a la estética de los clubes o comunidades leather, objeto de exaltación y fascinación de Pablo, podrían adjudicársele, al menos a nivel teorético, estas mismas características mencionadas anteriormente. El leather no funcionaría en El mendigo chupapijas como una segunda piel sino como un artificio complejo que, además del representativo disfraz o uniforme, reúne diversos dispositivos que tienen una utilidad precisa en el juego de placer y dominación: "máscaras de cuero y antigases, pinzas para las tetillas, broches, una fusta y otros tipos de látigos, dildos, popper, habanos, marihuana, hachís, etc.” (Pérez 2005: 31). Sin olvidar que estas sociedades tienen una simbología identitaria (e.g.: una bandera propia). Así, la exacerbación del artificio en las comunidades leather llega a erigirse como código o reglamentación a cumplimentar para poder acceder a las mismas, como dress-code obligatorio para el intercambio SM o BDSM.

Este tipo de prácticas, que en el dungeon de Báez que frecuenta Pablo se dan solamente entre varones, suponen dos roles de poder definidos y desiguales (amo y esclavo) y el consentimiento de los participantes, que disfrutan de controlar la actividad, infligiendo dolor y humillando (al sumiso) o bien siendo el objeto de esa humillación. En Is the rectum a grave? [1987], Leo Bersani recoge críticamente una interpretación que ha surgido a propósito de las mismas, explicando que

Se ha sugerido en los últimos años que el estilo macho-gai $[\ldots]$ y que el sadomasoquismo gai o lésbico, lejos de expresar complicidades incalificables o incontrolables con un ideal de masculinidad brutal y misógino [...] son, en realidad, parodias subversivas de esas mismas formulaciones y 
comportamientos que parecen imitar (1995: 93).

Bersani se muestra escéptico respecto al alcance que podrían tener estas representaciones y prácticas en la subversión o insurrección de la conformación de la masculinidad hetero-normativa. Sin embargo, es menester notar que uno de los elementos constitutivos del camp es el uso crítico que hace de la forma paródica, a partir del cual se logra crear, tal como afirma Preciado, "un espacio de visibilidad propio a la cultura marica, bollera y trans, a través del reciclaje y la declinación paródica de modelos de la feminidad y la masculinidad de la cultura popular dominante (2004: 13).

\section{Kitsch y Parodia}

A diferencia de los juegos sexuales SM, que son narrados frecuentemente con un tono descriptivo y por momentos similar al del reporte o informe, el registro paródico en El mendigo chupapijas suele aparecer, antes bien, durante las invocaciones y experiencias místicas de Pablo, vinculadas a su suerte en el amor. Por un lado, durante las experiencias masoquistas sexo-corporales, Pablo exalta la técnica suspensiva como una forma de incrementar el placer: "Los pasos severos, el sonido grave de las botas contra el piso de madera, sonaban como las pisadas de un gigante. Cada paso se prolongaba en el tiempo y mi deseo crecía” (Pérez 2005: 13). Sin embargo, por otro, la ausencia del amado, Martín, y la incertidumbre que ésta trae aparejada para Pablo, es vivida como una "infelicidad total" (Pérez 2005: 63), efecto de un veneno poderoso, que le causa arrepentimiento, deseando no haberse involucrado nunca con él.

En ocasión de la llegada del romance y el amor a la vida de Pablo, se multiplican las frases cursis, reminiscencias de un histrionismo melodramático:

Mientras él me besaba sentía que un dios había bajado del cielo a darme ese momento único, bello, la energía de un amor desbordante, ilimitado. Mi corazón quedaba al descubierto, más sensible que nunca. ‘Me gusta -le dije-. Quisiera morir de ese veneno’ (Pérez 2005: 63).

$\mathrm{Al}$ ser consciente de que por momentos una voz kitsch que recuerda a las altamente consumidas novelas románticas se apodera del relato, el mismo Pablo pretende sustraerse de ella, asumiendo que se trata de algo “estúpido” y de “tonterías” (Pérez 2005: 73).

Tal como remarca Yuszczuk (2015), retomando los aportes de Daniel García Helder y Martín Prieto, uno de los rasgos en común que compartirían los textos publicados por Belleza y Felicidad sería cierto tratamiento estetizado de lo kitsch, hecho "como por modistas", el cual, a diferencia del heroísmo que éste adquiere en la obra de Perlongher, ya "no libra batallas” (García Helder \& Prieto 1998, citado en Yuszczuk 2015: 23). La extemporaneidad, entre otros factores, distanciaría en este sentido a ambos autores.

Sin embargo, en la narración de las vivencias de Pablo parece entreverse la figura del "flâneur homosexual" (Perlongher 2013a: 134), concepto que Perlongher atribuye a Glauco Mattoso ${ }^{6}$, a propósito de los cargados recorridos callejeros de sus relatos, sobre los cuales él mismo se interesó tanto en sus estudios en ciencias sociales como en su producción literaria. $\underline{7}$ "El glaucomatoso", sostiene Perlongher, "significa el goce donde socialmente solo está instalado, reconocido, legitimado, el desprecio y el asco" (Perlongher 2013a: 136) . Pérez retoma esta tradición literaria que hace del paseante un habitante ineludible de la ciudad y El mendigo chupapijas nos ofrece el variopinto panorama de una Buenos Aires leather y queer en su máxima expresión; en cuanto al mendigo chupapijas, éste personifica esa sobreabundancia del goce no regido por la economía del intercambio de placeres.

Pérez debe, no obstante, lidiar con lo kitsch de sus propias experiencias en las que "nada estaría demás" e intenta sortearlo invocando lo que Sade denominó “le principe de délicatesse” (Delon 2011: 15). Esta 
delicadeza de los amos ${ }^{\underline{9}}$, inspirada en el cuidado hacia el sumiso o el esclavo, se retrotrae y se fundamenta en la neutralidad a partir de la cual deben observarse todos los gustos y las pasiones para poder ponderarlos a todos por igual. Porque, después de todo, el amo masoquista está volcado hacia un goce que en principio le es ajeno: el goce del Otro (del siervo); toda su autoridad proviene de la voluntad de delegación de ese otro.

Sin esta base de légèreté, una de las principales herencias del siglo XVIII libertino, no se podría aceptar o inclusive elogiar la bizarrerie en la cual consiste el factum de la singularidad del goce de cada quien. Pérez es, como Sade, aquel que se permite escribirlo todo, pero, a su vez, para describir el itinerario masoquista de Pablo, todo rastro del amo-Pérez tiende necesariamente a desaparecer debido a la impersonalidad y a la desubjetivación que exige el rol mismo, el cual debe ser supuesto a la manera de un trascendental. Quizás por eso no existen más que insinuaciones de que éste alguna vez formó parte del relato en El mendigo chupapijas. 10

Ahora bien, Pérez despliega, a partir de esta ligereza, recursos varios para lograr sortear lo kitsch; principalmente, su escritura lúdica y décontractée que no se toma a sí misma del todo en serio. Para desarrollar este punto, convendría concentrarnos en su inspiración flaubertiana, la cual nos permite observar la ironía en la alusión al kitsch de Pérez.

En su tránsito hacia la conversión místico-religiosa, Pablo construye un altar en su dormitorio, con velas e incienso, dedicado a San Jorge, patrón de los enamorados, luego de presenciar el choque de un pájaro contra el parabrisas del colectivo en donde viajaba, el cual interpreta como un "mal signo" (Pérez 2005: 66) y una metáfora del estado actual de su corazón. Similarmente, la nostalgia por las aves y los pajarones surge en el cuento Un cour simple (en Trois contes), en el cual Felicité, una criada y autómata de la modestia, eleva un altar para su amado loro embalsamado, figura paródica del espíritu santo. Esta popularización y teatralización de la religión se manifiesta también en las líneas que Pablo transcribe de La tentation de Saint Antoine de Flaubert para expresar cómo se habían despertado en él los sentimientos de mártir, aunque en el contexto de la mundanidad de su vida amorosa. De esta forma, el acoso nocturno de feroces bestias lo hacen desear un retiro perpetuo, el cual, a diferencia de las desoladas ruinas en donde padecía San Antonio, tendría lugar en su dormitorio. El mendigo chupapijas va tornándose así en una hagiografía kitsch, cuyo desenlace aúna el lenguaje bastardeado de la mística de autoayuda con el silencio y la laetitia ante la sublimidad de lo maravilloso.

\section{Conclusión}

Una vez producida la ruptura entre el comisario Báez y José, la pareja SM con quien Pablo tenía sexo leather, el equilibrio dinámico entre la experimentación sexual sado-masoquista de Pablo (personificado en Báez) y su tendencia hacia el imaginario kitsch y hacia el amor romántico idealizado (personificado en José) se quiebra, llevando a Pablo a una existencia lumpen. Esta tensión entre ambos polos genera un desequilibrio que dispara la narrativa de la intimidad de Pablo en su tránsito hacia la paz, al cual seguimos no sólo en sus encuentros sexuales sino en sus momentos de soledad, en sus ejercicios de visualización, en sus reflexiones y cravings. Sin embargo, no se trata de la mera intimidad sin más sino de "la intimidad impersonal propia de un arte: el arte de la existencia (soy esta loca, tengo esta voz) vuelto asunto de escritura” (Link 2013: 9).

En este sentido, El mendigo chupapijas no sería ajena al fenómeno de la postautonomía atribuida a las literaturas contemporáneas las cuales, según Josefina Ludmer, intervienen en la imaginación pública proponiendo y evidenciando una nueva manera de concebir y experimentar (los límites entre) la realidad y la ficción. Ya no se puede escindir a éstas tan fácilmente sino que se han conjugado en lo que Ludmer llama “realidadficción”, la cual “incluye el acontecimiento pero también lo virtual, lo potencial, lo mágico y lo fantasmático; es una realidad que no quiere ser representada o a la que corresponde otra categoría de 
representación" (Ludmer 2007), interpretada por Palmeiro como una realidad que "no aparece bajo la pretensión realista de totalidad estructurante sino como un 'territorio' de representación (no a representar)" (Palmeiro 2011: 163).

Con todo, el cambio atañe no sólo al estilo en el cual se escribe lo real (ficticio) sino, enfáticamente, a la forma en que se lo lee, a la actitud que se tiene frente a él.

Así, El mendigo chupapijas se apropia de ciertas escrituras de lo real como el diario íntimo o la transcripción de emails instalando cierta vacilación (¿Se tratará o no de intercambios o eventos que realmente ocurrieron? ¿Acaso la novela fue escrita por un mendigo?) y regocijándose en la falta de respuestas contundentes. La obra se posa entonces sobre esa ambivalencia entre "un yo del diario íntimo que a veces se vuelve residuo y la tercera persona, entre lo individual y lo impersonal, para proponer como escenario del presente ese juego de desdiferenciación entre el sujeto y los procesos de singularización” como sostiene Juan Marguch (2011). Así, como relato de un sujeto en permanente proceso, como despliegue de un yo atravesado por distintos dispositivos de poder, El mendigo chupapijas se presta a lo que Link llama yolleo, cierto tratamiento del yo que en definitiva explica aludiendo a una frase de Giordano, como expresión del deseo de "experimentación de la propia rareza” (Link 2009: 409).

Para finalizar, sería necesario volver sobra la importante tópica del masoquismo. En efecto, el yolleo postautónomo de Pérez en El mendigo chupapijas tiene la urgencia de un rally cuya meta sería "descargar toda esta leche mental e hirviente” (Pérez 2005: 16). Lejos del deber autoimpuesto de la escritura que observamos en Un año sin amor, el Pablo del Mendigo chupapijas encuentra en ella un goce catártico que le permite celebrar todas sus vulnerabilidades.

El triunfo del yo de Pablo en El mendigo chupapijas representa entonces, ante todo, la victoria del yo masoquista ante el superyó o la Ley. En este sentido, la fascinación que la obra de Pérez suscita parece generarse a partir de esta actitud infinitamente lúdica del yo queer, que está permanentemente en fuga respecto de las Huestes Enemigas de la Moral. Más aún, dicha actitud de Pablo no se explica sino como humor masoquista, esto es: como una burla a la interdicción, que se vuelve exterior e irrisoria sirviendo los fines del yo triunfante (Deleuze 1969: 110). El masoquista es, tal como explica Deleuze, "rebelde por sumisión” (Deleuze 1969: 80) ya que convierte la punición que la Ley impone para aquellos que la transgreden en condición del placer prohibido, ridiculizando la fuerza de la interdicción.

Este posicionamiento irónico ante el castigo expulsivo en el que concluye el asedio de la moral heteronormativa hacia la persona de Pablo le permite a Pérez contar la historia de la transformación hacia la feminidad y la mendicidad como una historia de redención y júbilo. La catábasis hacia estos dos inframundos sociales, tradicionalmente asociados a la pasividad y desprovistos de poder, es en realidad vivida por Pablo como una anábasis, como un ascenso al ámbito de los seres celestiales que brillan a su alrededor, y como la resurrección de una nueva (pero al mismo tiempo antigua) forma de vida: Paulita. El efecto de shock nos persigue y acorrala a cada paso de la transformación. Sin embargo, el fervoroso deleite de ser quien uno es lo supera todo en una novela en la cual se trata de vivir, ante todo.

\section{NOTAS}

1 Si bien se suele identificar a Gabriela Bejerman como otra de las co-fundadoras de Belleza y Felicidad por la multiplicidad de proyectos y afinidades compartidos con Laguna y Pavón, tanto Marina Yuszczuk (2015: 23) como Cecilia Palmeiro (2011: 171) aclaran que no fue así. Pavón se habría desvinculado de ByF alrededor de 2002. 
$\underline{2}$ Existen intérpretes como Anahí Mallol (2006) que sostienen la tesis contraria, i.e., que los proyectos como ByF o Eloísa Cartonera se reducen a una provocación sin más. Mallol sostiene al respecto que: “...[su proyecto] provocador y divertido, en la estela de las vanguardias, parece destinado a agotarse en su propio gesto, en la medida en que posee un único significado: la vacuidad del gesto mismo (lo que quiere decir: aceptación del fracaso de las vanguardias, imposibilidad de relacionar al arte con la vida, falta de función del artista en la sociedad, falta de función social y aún humana de la poesía, etc.)" (Mallol, 2006). Por el contrario, lo que proponemos en este artículo es observar el tratamiento literario que se le da en estos proyectos a las identidades queer como un gesto de injerencia política que tiende a hacer visibles formas de vida y subjetividades previamente soterradas.

3 Además, Fernanda Laguna logró abrir otra sucursal de la galería en Villa Fiorito en 2003, gracias a su fortuito encuentro con Isolina Silva, "la negra”, una señora cartonera que dirigía allí el comedor Pequeños traviesos. ByF encarga al comedor bolsitas de tela para envolver los libros de la editorial. Durante ese mismo año, se crea Eloísa Cartonera, la editorial, en donde trabajaban, entre otros, los hijos de la negra: David, Daniel y Alberto. A su vez, Laguna comenzó a alquilar una habitación de la casa de Isolina, donde se realizaban exposiciones e intervenciones artísticas, a cambio de alimentos para el comedor. Luego el proyecto creció y se convirtió en una escuela de arte. La información fue obtenida del blog de la misma escuelita: http://bellezayfelicidadfiorito.blogspot.com.ar/.

4 Así se describe Pablo a sí mismo en varias ocasiones, principalmente en Un año sin amor.

$\underline{5}$ Inclusive el soporte, el material en que se nos aparece esta nueva forma de literatura, resulta (novedosamente) trash (Mazzoni y Selci, 2006): ByF produce "libritos fotocopiados” y Eloísa Cartonera, ediciones realizadas con cartón.

6 Glauco Mattoso es el pseudónimo de Pedro José Ferreira da Silva, un prolífico escritor brasileño nacido en São Paulo en 1951. Desde su condición de portador de glaucoma, este poeta, ensayista y narrador de ficción se abre en su obra a la experimentación de nuevas formas de subjetividad que surgirían a partir de formas "marginales” de vivir la sexualidad. Fue junto con João Silvério Trevisan el fundador del movimiento SOMOS en 1978, una agrupación gay, pionera en Brasil, que se habría inspirado en el Frente de Liberación Homosexual, liderado, entre otros, por Néstor Perlongher (disuelto en Argentina a causa del golpe militar del año76).

7 Néstor Perlongher (1949-1992) fue un activista por los derechos de los homosexuales, poeta, ensayista, docente e investigador en sociología y antropología social. Se traslada a Brasil a principios de la década de los 80 y se desarrolla como profesor en la Universidade Estadual de Campinas. Su tesis de maestría trató sobre el fenómeno de la prostitución masculina en São Paulo (fue posteriormente editada como libro). Definió su estilo poético como "neobarroso", un cruce entre el "neobarroco" y el barro del Río de la Plata. Cf. Perlongher (2013b).

$\underline{8}$ Si bien la cita fue extraída de la compilación realizada por Christian Ferrer y Osvaldo Baigorria de la obra de Perlongher, el texto en cuestión fue publicado por primera vez como el Postfacio a Manual do podólatra Amador. Aventuras \& lecturas de un tarado por pés de Glauco Mattoso (1986).

9 La relación amo-esclavo remite esencialmente al masoquismo, mientras que, por el contrario, en la obra novelística de Sade, encontramos dos tipos de figuras bien diferenciadas: el libertino o la libertina, por un lado, y su presa, por otro, i.e., el victimario y su víctima. Esta última será perseguida, raptada y aniquilada en el proceso de goce de su verdugo y nunca cesará de ser el objeto de deseo a los ojos de su captor (nunca es humanizada o vista como sujeto de deseo en la obra del Marqués). El masoquismo plantea, en cambio, una vinculación consensuada, pactada, entre dos participantes distintos; el amo es quien debe organizar la escena 
para la satisfacción del siervo, que a su vez relega en él (o en ella) tal responsabilidad. En este sentido, el amo es similar a Sade, considerado como "fonction auteur" (Foucault 1994), y no tanto a sus personajes libertinos. "Sadismo” y "masoquismo” son, según Deleuze, dos entidades clínicas marcadamente distintas (no sólo en lo que respecta a la sintomatología o a la forma del goce atribuible a cada caso sino también en lo que concierne a la estética literaria de Sade y Masoch).

10 De hecho, no encontramos allí ni una escena en donde Pablo desempeñe el rol dominante en una relación SM a pesar de que, a través de ciertas transcripciones de las conversaciones con Báez, sabemos que en efecto convertirse en amo era algo que Pablo deseaba y que termina cumpliendo.

\section{BIBLIOGRAFÍA}

Aira, César (2002). "Los poetas del 31 de diciembre de 2001”. El país, 7 de febrero. Recuperado de: http://elpais.com/diario/2002/02/09/babelia/1013215161 850215.html

Amícola, José (2000). Camp y posvanguardia: Manifestaciones culturales de un siglo fenecido, Buenos Aires, Paidos.

Bersani, Leo (1987). "Is the Rectum a Grave?”, en October, Vol. 43 “AIDS: Cultural Analysis/Cultural Activism”, pp. 197-222.

Bersani, Leo (1995). “¿Es el recto una tumba?”, en Ricardo Llamas (ed.), Construyendo identidades. Estudios desde el corazón de una pandemia, pp.79-115, Madrid, Siglo XXI.

Butler, Judith (1993). Bodies that matter: On the discursive limits of sex, New York, Routledge.

Butler, Judith (2002). Cuerpos que importan. Sobre los limites materiales y discursivos del "sexo", Buenos Aires, Paidós.

Deleuze, Gilles (1967). Présentation de Sacher-Masoch. Le froid et le cruel, Paris, Minuit.

Deleuze, Gilles (1969). Sacher-Masoch y Sade, Córdoba, Editorial universitaria de Córdoba.

Delfino, Silvia (2001). “Introducción”, en AA. VV., Aventuras. Nuevas incursiones en el imaginario gay, Buenos Aires, Belleza y Felicidad.

Delon, Michel (2011). Le principe de délicatesse: libertinage et mélancolie au XVIII siècle, Paris, Albin Michel.

Foucault, Michel (1976). Histoire de la sexualité I: La Volonté de savoir, Paris, Gallimard.

Foucault, Michel (1994). Dits et écrits: 1954-1988, vol. 3, Paris, Gallimard.

García Helder, Daniel y Martín Prieto (1998). "Boceto n² para un .... de la poesía argentina actual”, en Punto de Vista, N $^{\circ}$ 60, pp. 13-18.

Link, Daniel (2009). Fantasmas. Imaginación y sociedad, Buenos Aires, Eterna Cadencia.

Link, Daniel (2013). Kitsch, camp, boom: Puig y el ser moderno, conferencia-performance pronunciada en el marco del ciclo de debates "CAMP! - Afetos e Poses”, organizado por la UERJ (Río de Janeiro), en mesa plenaria compartida con Silviano Santiago y coordinada por Italo Moriconi. Recuperado de: https://www.academia.edu/6458921/ Kitsch camp boom Puig y el ser moderno Daniel Link 
Ludmer, Josefina (2007). "Las literaturas postautónomas", en CiberLetras. Revista de crítica literaria y cultura, vol. 17. Recuperado de: http://www.lehman.cuny.edu/ciberletras/v17.html

Mallol, Anahí (2006). Nuevos formatos, nuevas lecturas: poesía, velocidad y consumo en los 90. Recuperado de: http://www.expoesia.com/j06 mallol.html

Marguch, Juan (2011). “La máquina amorosa: El mendigo chupapijas”, en No-retornable, vol. 8. Recuperado de: http://www.no-retornable.com.ar/v8/dossier/marguch.html

Mattoso, Glauco (1986). Manual do podólatra Amador. Aventuras \& lecturas de un tarado por pés. São Paulo: Expressão.

Mazzoni, Ana y Damián Selci (2006). "Poesía actual y cualquierización”, en Jorge Fondebrider (comp.), Tres décadas de poesía argentina, 1976-2006, pp. 257-268, Buenos Aires, Libros del Rojas.

Palmeiro, Cecilia (2008). Lixeratura Argentina Contemporánea: Pensamiento Queer en Antiestéticas do Trash, trabajo presentado en el XI Congresso Internacional da ABRALIC: Tessituras, Interações, Convergências realizado en la Universidade de São Paulo. Recuperado de: http://www.abralic.org.br/eventos/cong2008/AnaisOnline/simposios/pdf/068/CECILIA PALMEIRO.pdf

Palmeiro, Cecilia (2010). Desbunde y felicidad: de la Cartonera a Perlongher, Buenos Aires, Título.

Pérez, Pablo (2005). El mendigo chupapijas, Buenos Aires, Mansalva.

Pérez, Pablo (2015). Un año sin amor, Buenos Aires, Blatt \& Ríos.

Perlongher, Néstor (1988). El fantasma del sida, Buenos Aires, Puntosur.

Perlongher, Néstor (2013a). "El deseo de pie”, en Christian Ferrer y Osvaldo Baigorria (eds.), Prosa Plebeya, pp. 132-143, Buenos Aires, Excursiones.

Perlongher, Néstor (2013b). “Caribe Transplatino. Poesía neobarroca cubana e rioplatense”, en Christian Ferrer y Osvaldo Baigorria (eds.), Prosa Plebeya, pp. 119-131, Buenos Aires, Excursiones.

Preciado, Paul (2004). “Género y performance. 3 episodios de un cybermanga feminista queer trans”, en Parole de queer. Recuperado de: http://paroledequeer.blogspot.com.ar/2015/08/beatriz-preciado3-episodiosde-un.html.

Quignard, Pascal (2014) [1969]. L'Être du balbutiement. Essai sur Sacher-Masoch, Paris, Gallimard.

Sontag, Susan (2008) [1964]. “Notas sobre lo camp”, en Horacio Vázquez Rial (trad.), Contra la Interpretación y otros ensayos, pp. 351 - 372, Buenos Aires, Debolsillo.

Yuszczuk, Marina (2015). "Belleza y Felicidad en la vorágine del 2001: algunas percepciones contemporáneas sobre las condiciones de un arte político”, en Orbis Tertius, vol. 20 (21), pp. 21-29. http://www.orbistertius.unlp.edu.ar/article/view/OTv20n21a03/6806 